\title{
Maternal serum selenium as a predictor of preeclampsia
}

\author{
Vismaya Kaveri', Manjula S. K.*1, Sheela C. N.1, Anura Kurpad², Pratibha Dwarkanath ${ }^{2}$
}

\begin{abstract}
${ }^{1}$ Department of Obstetrics and Gynecology, Yenepoya Medical College, Mangalore, Karnataka, India
${ }^{2}$ Department of Physiology, Division of Nutrition, St. John's Research Institute and Medical College, Bangalore, Karnataka, India
\end{abstract}

Received: 02 September 2018

Accepted: 28 September 2018

*Correspondence:

Dr. Manjula S. K.,

E-mail: thatva@rediffmail.com

Copyright: (C) the author(s), publisher and licensee Medip Academy. This is an open-access article distributed under the terms of the Creative Commons Attribution Non-Commercial License, which permits unrestricted non-commercial use, distribution, and reproduction in any medium, provided the original work is properly cited.

\begin{abstract}
Background: Preeclampsia (PE) is a hypertension disorder condition occurring in $7-10 \%$ of all pregnancies. Preeclampsia if unidentified and left untreated is associated with poor maternal and fetal adverse outcomes. The objective of the present study was to characterize maternal serum selenium levels as a predictor of preeclampsia and to correlate dietary selenium intake with serum selenium levels in first trimester of pregnancy

Methods: A retrospective case-control study of 107 pregnant women was conducted over 1.5 years at St. John's Medical College Hospital. On screening for inclusion criteria, at baseline, information on maternal sociodemography, anthropometry, dietary intake and clinical examination was collected. A venous blood sample at baseline and 2nd or 3rdtrimester of pregnancy was collected for estimation of selenium concentrations. Blood pressure was measured at baseline and followed up during pregnancy to select cases and controls. Pregnant women were termed 'cases' based on NHBPEP (National High Blood Pressure Education Program) classification and subsequent 22 women with normal blood pressure controlled for age were termed as 'controls.

Results: No statistically significant differences were observed for baseline characteristics, biochemical parameters and blood pressure at recruitment among cases and controls. Cases had significant lower levels of energy $(\mathrm{P}=0.032)$ and micronutrients like zinc $(\mathrm{P}=0.027)$, selenium $(\mathrm{P}=0.022)$, magnesium $(\mathrm{P}=0.047)$ at first trimester. The serum selenium levels were significantly higher in cases as compared to the controls $(69.2 \pm 13.7$ vs. $59.6 \pm 12.9 ; \mathrm{P}=0.021)$ at baseline.

Conclusions: Our findings suggest that serum selenium levels may not be an independent predictor of preeclampsia. Assessment of other micronutrients, oxidative stress markers and other complementary elements may be useful in predicting preeclampsia.
\end{abstract}

Keywords: First trimester, Predictor, Preeclampsia, Selenium status

\section{INTRODUCTION}

Hypertensive disorder of pregnancy remains a major concern in obstetric care, which has been a challenge to obstetricians and researchers since many decades. Preeclampsia occurs in nearly $7-10 \%$ of all pregnancies and is a condition which when not identified and left untreated is associated with poor maternal and fetal adverse outcomes. It is essential to diagnose and adequately treat the elevated blood pressure before 34 weeks of gestation as the trophoblastic invasion of the placenta occurs in the 2nd trimester and abnormality of it will affect the growth of the fetus. ${ }^{1}$ About $10-25 \%$ of maternal death in developing countries is associated with preeclampsia and being complicated with seizures called as eclampsia. ${ }^{2}$ Placental implantation with abnormal trophoblastic invasion of uterine vessels is one of the theories in etiopathogenesis of preeclampsia. ${ }^{3}$ A number of parameters have been studied as a predictor of preeclampsia, which are related to placental perfusion, 
vascular resistance, fetal placental unit, endocrine dysfunction, renal dysfunction and oxidant stress. ${ }^{4}$ Though the risk factors are well known, there are no biomarkers that can predict and prevent the onset of preeclampsia. ${ }^{5}$

Selenium (Se) is an essential trace element found as a component of glutathione peroxidise (GPx), a selenoprotein, which protects the endothelium byscavenging on oxidation products of hydroperoxides and lipoperoxides. ${ }^{6}$ Selenium- dependent GPx's plays a key role in protection against oxidative damage, and have been shown to have reduced activity during pregnancy, with the lowest activity at delivery. ${ }^{7}$ Activity of the selenoproteins is determined by activity/ translation of the relevant genes, among which a number of singlenucleotide polymorphisms (SNPs) are described in nonpregnant subjects, including some with reported effects on gene expression, mRNA translation, or protein stability. ${ }^{8-10}$ Preeclampsia has a familial component, but it is not known whether these SNPs could, independently or in association with lower selenium status, be determinants of the putative impairment in antioxidantdefence. ${ }^{11}$

Utility of serum selenium lies in its ability to predict the onset of preeclampsia, which allows for screening of a subpopulation that is at a higher risk to end up with poor maternal and neonatal outcomes. Observational studies have shown an association of preeclampsia with low levels of serum selenium. ${ }^{12}$ Although there is dearth of data, a randomised controlled trial in UK, SPRINT (Se in Pregnancy Intervention) was conducted to measure the effect of dietary selenium supplementation (i.e., $60 \mu /$ day) on the markers of preeclampsia, endothelial and placental function. $^{13}$ A reduced incidence of preeclampsia was noted in the selenium supplemented group compared to the placebo group. ${ }^{14}$ This study was therefore conducted in a South Indian pregnant woman to evaluate the role of selenium status in early pregnancy on preeclampsia.

\section{METHODS}

\section{Study design}

A retrospective case-control study was conducted at the out-patient unit of Obstetrics and Gynaecology department, St. John's Medical College Hospital, Bangalore, India, from December 2014 to May 2016. Pregnant volunteers were enrolled in early pregnancy (baseline) and followed up until delivery. At recruitment, information on socio-demography was collected by the trained researchers, maternal anthropometry, dietary intake, clinical status and venous blood sample was collected at baseline and during second or third trimester of pregnancy. Blood pressure was measured at baseline and followed up during the course of pregnancy to select cases and controls. Mean arterial pressure (MAP) is an average blood pressure in an individual during a single cardiac cycle. It was calculated using the following formula i.e. $\mathrm{MAP}=[(2 \mathrm{x}$ diastolic $)+$ systolic $] / 3$. Those women who met the classification of preeclampsia as per NHBPEP15 were categorized as cases and matched for age, parity and education (an index of socio-economic status) with control subjects. The study procedure was approved by the Institutional Ethical Review Boards at St. John's Medical College Hospital. A written informed consent was obtained from each study subject at enrolment.

\section{Study subjects}

All pregnant women aged 18-40 years who were between 12 to14 weeks of gestation with singleton pregnancy and registered for antenatal screening were invited to participate in the study. Women with chronic hypertension, diabetes mellitus, peripheral vascular disease, thyroid disease, abnormal BMI (i.e., underweight, overweight or obese), sexually transmitted disease and having anomalous fetus (detected by anomaly scan) were excluded from the study Figure 1.

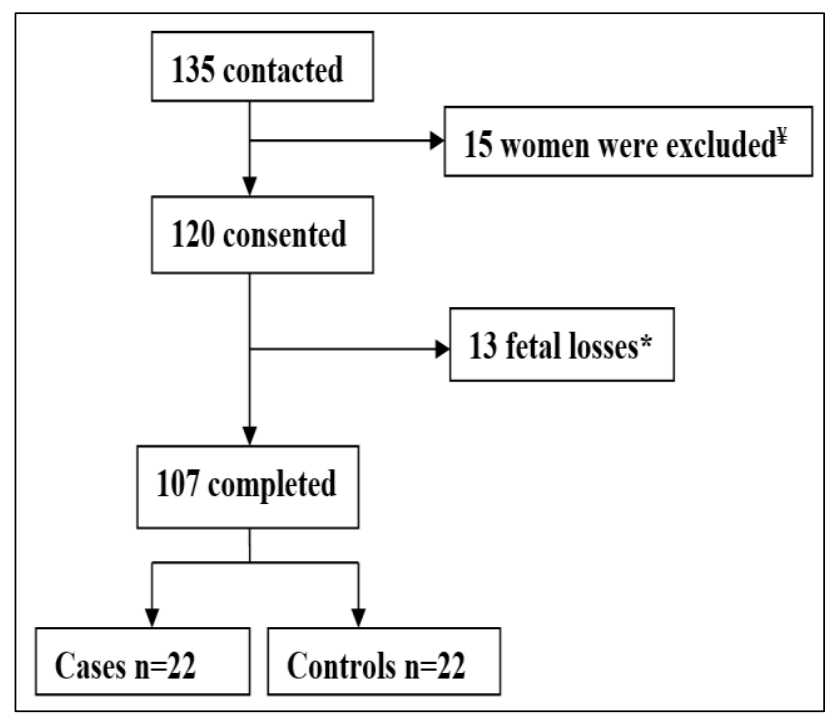

$¥-2$ HBsAg positive, 4 abnormal TSH, 4 low BMI, 5 high BMI.

*- includes spontaneous abortion and missed abortion.

Figure 1: Flow diagram of recruitment and follow-up in the study cohort.

\section{Socio-demographic and anthropometric information}

At the first trimester visit, baseline information on socioeconomic status (SES) such as age, education, parity, obstetric history and family composition was collected. Gestational age (in weeks) was calculated from the reported first day of the last menstrual period (LMP) which was subsequently confirmed by ultrasonographic measurement. All antenatal women were measured for weight to the nearest $100 \mathrm{~g}$ by a digital balance (Soehnle, Germany). They were also subjected for measurement of height using a stadiometer to the nearest $1 \mathrm{~cm}$ at baseline. Subsequently maternal body mass index (BMI) was calculated using weight and height at baseline $\left(\mathrm{kg} / \mathrm{m}^{2}\right)$. 


\section{Biochemical parameters}

Venous blood was drawn from all study subjects by venipuncture using trained personnel and collected in plain vaccutainers (Beckton Dickinson), for the analysis of serum selenium $1 \mathrm{ml}$ of serum was stored in a plain vaccutainer at $-80^{\circ} \mathrm{C}$ until analysis. As per the routine antenatal screening, whole blood was used for the measurement of haemoglobin and other baseline parameters like fasting blood sugar and TSH (Thyroid stimulating hormone) level were also estimated. Serum selenium was analyzed after preparation of the sample by diluting 1:1 (200 $\mu \mathrm{L}$ sample $+200 \mu \mathrm{L}$ conc. Nitric acid). Then the sample was centrifuged at $500 \mathrm{rpm}$ for 5 minutes. The supernatant was taken as sample for Selenium estimation on atomic absorption spectroscopy (AAS). The concentrations obtained on AAS were multiplied by a factor of 2 .

\section{Dietary methods}

A validated food frequency questionnaire (FFQ) during pregnancy was administered at recruitment to obtain information on habitual dietary intake for the preceding 3months.16In brief; the questionnaire consisted of 108 items, along with portion sizes and frequency.

Standard measures were placed before the respondent to quantify the portion size of each food item when administering the questionnaire. Recipes for the food items were tested in the laboratory and raw ingredients for each recipe were weighed, and volume to weight conversions measured for each cooked food item.

\section{Statistical analysis}

Continuous data was represented as mean \pm standard deviation (SD) and the categorical data as number (percentages). Chi square test of significance was applied for the categorical variables and independent t-test was applied for continuous variables to observe the differences between variables across cases and controls. Two-sided P-values of $<0.05$ were considered statistically significant. All analysis was performed on excel and SPSSv18.0 (PASW Statistics, SPSS Inc., Chicago, IL, USA).

\section{RESULTS}

The mean age of the study subjects was around 26 years. Table 1 describes the socio-demographic, anthropometric and clinical parameters of the cases and control subjects. Maternal parameters such as parity and socio-economic status were compared between the two groups using Chi square test.

High number of cases were pregnant for the first time as compared to the controls (54.4 Vs $45.5 \%$; $\mathrm{P}<0.382)$. Further it was observed that higher percentage of cases belonged to lower SES as compared to the controls (54.0 Vs $59.0 \%, p<0.500)$. However, statistically significant difference was not noted.

Table 1: Sociodemographic, anthropometric and clinical parameters.

\begin{tabular}{|c|c|c|c|}
\hline Parameter & Cases $($ mean \pm SD) $n=22$ & Controls (mean \pm SD) $n=22$ & $P$ value \\
\hline Age & $25.9 \pm 4.1$ & $25.9 \pm 4.1$ & 1.000 \\
\hline \multicolumn{4}{|l|}{ Parity } \\
\hline Nulliparous & $12(54.4 \%) *$ & $10(45.4 \%)^{*}$ & \multirow{2}{*}{0.382} \\
\hline Multiparous & $10(45.4 \%)^{*}$ & $12(54.4 \%)^{*}$ & \\
\hline \multicolumn{4}{|l|}{ Socioeconomic status } \\
\hline Upper & $10(45.4 \%)^{*}$ & $9(40.9 \%) *$ & \multirow{2}{*}{0.500} \\
\hline Lower & $12(54.4 \%)^{*}$ & $13(59.09 \%)^{*}$ & \\
\hline $\operatorname{BMI}\left(\mathrm{kg} / \mathrm{m}^{2}\right)$ & $22.4 \pm 1.8$ & $21.2 \pm 2.2$ & 0.06 \\
\hline \multicolumn{4}{|c|}{ Blood pressure in $1^{\text {st }}$ trimester } \\
\hline Systolic & $114.4 \pm 9.8$ & $113.5 \pm 7.9$ & 0.763 \\
\hline Diastolic & $73.9 \pm 6.8$ & $72.5 \pm 5.8$ & 0.450 \\
\hline Mean arterial pressure & $87.4 \pm 6.9$ & $86.2 \pm 5.6$ & 0.515 \\
\hline \multicolumn{4}{|c|}{ Blood pressure in $2^{\text {nd }} / 3^{\text {rd }}$ trimestr } \\
\hline Systolic & $153.2 \pm 8.3$ & $122.1 \pm 7.3$ & 0.000 \\
\hline Diastolic & $96.1 \pm 2.1$ & $72.8 \pm 4.3$ & 0.000 \\
\hline Mean arterial pressure & $115 . \pm 3.9$ & $89.2 \pm 4.4$ & 0.000 \\
\hline \multicolumn{4}{|l|}{ Proteinuria } \\
\hline $1+$ & $17(77.27 \%)^{*}$ & & \\
\hline $2+$ & $2(9.09 \%)^{*}$ & & \\
\hline $3+$ & $3(13.63 \%)^{*}$ & & \\
\hline
\end{tabular}


All the subjects at recruitment had anthropometrical measurements such as height and weight to estimate their body mass index (BMI). Maternal BMI was higher in the cases although was not statistically significant. However, the anthropometrical measurements did not show statistically significant difference between the 2 groups. The mean systolic, diastolic and mean arterial pressures of both cases and controls were equivalent with no significant difference in the first trimester.

Mean arterial pressure of $86.2 \pm 5.6$ and $87.4 \pm 6.9$ was noted in the controls and cases group respectively. This depict that to begin with there was no difference between the controls and cases. Whereas, the mean systolic, diastolic and mean arterial pressures of the cases were significantly elevated in second/third trimester. Mean arterial pressure was $89.2 \pm 4.4 \mathrm{mmHg}$ in controls and $115.1 \pm 3.9 \mathrm{mmHg}$ in cases with $\mathrm{P}=0.000$. This indicates that the cases had significantly elevated blood pressure in the second or third trimester after diagnosis of preeclampsia. Further, the cases were categorized into mild and severe preeclampsia by assessing their urine protein levels by dipstick method at diagnosis. It was observed that $77.2 \%$ of the cases had mild preeclampsia and $22.7 \%$ progressed to severe preeclampsia. The dietary patterns of the subjects were assessed using a validated $24 \mathrm{hr}$ dietary recall and the diet intake of macro- and micronutrient was compared (Table 2).

Table 2: Dietary pattern and intake of micro/ macronutrients.

\begin{tabular}{|c|c|c|c|}
\hline Parameter & Cases $($ mean \pm SD) $n=22$ & Controls (mean \pm SD) $n=22$ & P value \\
\hline \multicolumn{4}{|c|}{ - } \\
\hline Vegetarian & $2(9.09 \%)^{*}$ & $3(13.63 \%)^{*}$ & \multirow{2}{*}{0.500} \\
\hline Non-Vegetarian & $20(90.9 \%)^{*}$ & $19(86.3 \%)^{*}$ & \\
\hline \multicolumn{4}{|l|}{ Micro/Macronutrients } \\
\hline Energy (kCal/day) & $1504 \pm 457.06$ & $1839 \pm 542.8$ & 0.032 \\
\hline Protein (g/day) & $42.3 \pm 15.13$ & $52.8 \pm 15.8$ & 0.030 \\
\hline Fat (g/day) & $38.7 \pm 16.6$ & $51.6 \pm 17.8$ & 0.017 \\
\hline Carbohydrate (g/day) & $246.7 \pm 69.1$ & $291.0 \pm 84.8$ & 0.065 \\
\hline Copper (mg/day) & $1.5 \pm 0.51$ & $1.8 \pm 0.6$ & 0.053 \\
\hline Manganese (mg/day) & $4.4 \pm 1.91$ & $5.9 \pm 2.7$ & 0.052 \\
\hline Zinc (mg/day) & $6.5 \pm 2.1$ & $8.0 \pm 2.4$ & 0.027 \\
\hline Selenium ( $\mu \mathrm{g} /$ day $)$ & $45.3 \pm 15.5$ & $65.1 \pm 35.8$ & 0.022 \\
\hline Magnesium(mg/day) & $362.4 \pm 115.8$ & $441.2 \pm 138.5$ & 0.047 \\
\hline Vitamin E (mg/day) & $9.2 \pm 3.5$ & $12.5 \pm 4.3$ & 0.008 \\
\hline Vitamin C (mg/day) & $125.2 \pm 85.4$ & $119.5 \pm 81.87$ & 0.824 \\
\hline
\end{tabular}

*Number $(\%)$

It was observed that majority were non-vegetarians $88.6 \%$ (i.e., those who consumed meat and egg) whereas only $11.3 \%$ were noted to be vegetarians (i.e., those who consumed milk and did not consume egg). The control subjects had significantly higher macro nutrient intakes such as energy, protein and fats as compared to the cases (1839 vs. $1504 \mathrm{kcal} / \mathrm{d}, 52.8$ vs. $42.3 \mathrm{~g} / \mathrm{d}$, and 51.6 vs. 38.7 $\mathrm{g} / \mathrm{d}$ respectively).Of the micronutrients, intakes of zinc, selenium and magnesium were significantly lower in control subjects as compared to the cases $(8.0 \mathrm{vs}$. $6.5 \mathrm{mg} / \mathrm{d}, 65.1$ vs. $45.3 \mu \mathrm{g} /$ day and 441.2 vs. $362.4 \mathrm{mg} / \mathrm{d}$; all $\mathrm{p}<0.05$ respectively). In-addition to the micronutrients, intake of Vitamin $\mathrm{E}$; an antioxidant was significantly lower in the cases $(9.2$ vs. $12.5 \mathrm{mg} / \mathrm{d})$ although vitamin $\mathrm{C}$ did not show similar lower trend in the cases ( $125.5 \mathrm{vs} .119 .5 \mathrm{mg} / \mathrm{d})$.

The average serum selenium levels for the total population at baseline was $64.4 \pm 13.9 \mu \mathrm{g} / \mathrm{L}$, however the cases showed significantly higher levels when compared to the controls (69.2 vs. 59.6; $\mathrm{p}=0.021)$ (Table 3).
Table 3: Serum Selenium levels of the subjects in first trimester.

\begin{tabular}{|llll} 
Parameter & $\begin{array}{l}\text { Cases } \\
(\text { mean } \pm \text { SD }) \\
n=22\end{array}$ & $\begin{array}{l}\text { Controls } \\
(\text { mean } \pm \text { SD }) \\
n=22\end{array}$ & P value \\
Selenium & $69.2 \pm 13.7$ & $59.6 \pm 12.9$ & 0.021 \\
\hline
\end{tabular}

Table 4: Correlation of selenium intake with selenium status.

\begin{tabular}{|lll|} 
Selenium intake with & Cases & Controls \\
selenium status & $\mathrm{n}=22$ & $\mathrm{n}=22$ \\
& $\mathrm{r}=-0.145$, & $\mathrm{r}=-0.141$, \\
& $\mathrm{P}=0.519$ & $\mathrm{P}=0.533$ \\
\hline
\end{tabular}

However, all subjects' selenium intake negatively correlated with the selenium status; $\mathrm{r}=-0.213, \mathrm{P}=0.165$ (Table 4). There was no significant correlation observed between intake and selenium status neither in cases nor in controls with $\mathrm{r}=-0.145, \mathrm{P}=0.519 ; \mathrm{r}=-0.141, \mathrm{P}=0.533$ 
respectively. No significant correlation was observed with selenium intake or status at recruitment and blood pressure in 2nd trimester among cases and controls.

\section{DISCUSSION}

This case control study was conducted to evaluate the utility of serum selenium as a predictor of preeclampsia and to correlate the dietary selenium levels with the first trimester selenium levels. Number of maternal factors such age, parity, BMI, dietary pattern etc are identified as determinants of preeclampsia. Therefore, present study focused on evaluating maternal factors that included matched cases of preeclampsia with normotensive women for age and further at secondary level of matching with parity and socioeconomic status. Also, anthropometric measures of the study subjects were similar to that of other studies. ${ }^{11-12}$ The first trimester mean systolic, diastolic and mean arterial pressures of both controls and cases were statistically not different in the first trimester indicating that apparent healthy women were recruited in the study. The study subjects were followed up until delivery and those women who developed preeclampsia were observed to have had a rise of systolic blood pressure of $30 \mathrm{mmHg}$, diastolic blood pressure of $24 \mathrm{mmHg}$ and MAP of $26 \mathrm{mmHg}$ compared to the normotensive women in 2 ndor $3^{\text {rd }}$ trimester with $\mathrm{P}=0.000$. Among the cases, $77.3 \%$ had mild preeclampsia and $22.7 \%$ progressed to severe preeclampsia.

Selenium levels are thought to be higher in nonvegetarian diet and hence a protective measure against preeclampsia in women consuming non-vegetarian diet. In this population, the overall percentage of nonvegetarian consumers was high, however equal numbers of non-vegetarians were observed in cases and controls. This observation of higher non-vegetarians is similar to the findings by Rayman et al. ${ }^{17}$ The authors on examining the selenium levels showed no difference in Selenium status across the 2 groups of vegetarians and nonvegetarians' population. Our finding of similar dietary pattern was noted with predominance of non-vegetarian diet. We also studied the first trimester dietary pattern including macro and micronutrient intake, including correlation of dietary selenium intake with serum selenium levels of the subjects. We found significant difference in the macro and micronutrient including antioxidant like vitamin $\mathrm{E}$ between the 2 groups. It was observed that cases had significant lower levels of energy, selenium, zinc, magnesium and vitamin $\mathrm{E}$ as compared to the controls.

Cases had lower absolute intake of macro and micronutrients per day, assessed by validated FFQ (food frequency questionnaire) as compared to controls. The key observation was on selenium intake which was almost $20 \mu \mathrm{g} /$ day lower in cases, although, this trend was not observed in the selenium levels as a biomarker. We observed significantly lower levels of serum selenium at baseline in controls than the cases in these apparent healthy pregnant women. While evidences suggest that preeclamptic women in their third trimester tend to have lower levels in comparison to the normotensive pregnant women. ${ }^{12}$ Mistry et al further has shown association with micronutrients and antioxidant enzymes during early second trimester in preeclamptic women. ${ }^{11}$ However, they did not find reduced levels of selenium or selenoproteins. Although studies show directional changes of selenium concentrations among women with preeclampsia, these changes are well captured once the disease is set in, either in the 2nd or 3rd trimester as measured by the previous groups. In the anticipation of their role in preeclampsia it is observed that reduced selenium levels in third trimester is seen when the disease has already set in with oxidative stress playing its role, leading to excessive consumption of selenium by scavenging the oxidative products and protecting the fetus from free radical damage. This is not observed in first trimester sample as oxidative stress and second wave of placental angiogenesis occurs in 2nd trimester. Hence it leads to ambiguity whether the difference in serum selenium levels is due to the preeclampsia condition and selenium alone not an appropriate predictor marker especially for identification of preeclampsia in the1st trimester, prior to the onset of its pathogenesis.

\section{CONCLUSION}

Findings from present study suggest that serum selenium levels may not be an independent early predictor of preeclampsia. A cumulative assessment of other micronutrients, oxidative stress markers and other complementary elements along with selenium may be used for predicting preeclampsia.

\section{Funding: No funding sources}

Conflict of interest: None declared

Ethical approval: The study was approved by the Institutional Ethics Committee

\section{REFERENCES}

1. Lindheimer MD, Taler SJ, Cunningham FG (2010) Hypertension in pregnancy. J Am Soc Hypertens. 4(2):68-78.

2. Khan KS, Wojdyla D, Say L, Gulmezoglu AM, Van Look PF. WHO analysis of causes of maternal death: A systematic review. Lancet 2006; 367(9516):106674.

3. Redman CW, Sargent IL. Circulating microparticles in normal pregnancy and pre-eclampsia. Placenta. 2008;29(a):73-7.

4. Conde-Agudelo A, Romero R, Roberts JM. Tests to predict preeclampsia. In Chesley's Hypertensive Disorders in Pregnancy (Fourth Edition) 2015 (pp. 221-251).

5. Chamy VM, Lepe J, Cataln A, Retamal D, Escobar JA, Madrid EA. Oxidative stress is closely related to clinical severity of preeclampsia. Biol Res 2006;39(2):229-36. 
6. Rayman MP. The importance of selenium to human health. Lancet.2000;356(9225):233-41.

7. Mistry HD, Wilson V, Ramsay MM, Symonds ME, Broughton Pipkin F. Reduced Se concentration and glutathione peroxidase activity in preeclamptic pregnancies. Hypertens. 2008;52(5):881-8.

8. Combs GF, Watts JC, Jackson MI, Johnson LK, Zeng H, Scheett AJ, et al. Determinants of selenium status in healthy adults. Nut J. 2011;10(1):75.

9. Karunasinghe N. Han DY, Zhu S, Yu J, Lange K, Duan H. Serum selenium and single-nucleotide polymorphisms in genes for selenoproteins:relationship to markers of oxidative stress in men from Auckland, NewZealand. Genes Nutr 2012; 7(2):179-90.

10. Meplan C, et al.Functional effects of a common single-nucleotide polymorphism(GPX4c718t) in the glutathione peroxidise 4 gene: interaction with sex. Am. J. Clin. Nutr. 2008; 87:1019-27.

11. Mistry HD, Gill CA, Kurlak LO, Seed PT, Hesketh JE, Méplan C. Association between maternal macronutrient status, oxidative stress, and common genetic variants in antioxidant enzymes at 15 weeks' gestation in nulliparous women who subsequently develop preeclampsia. Free Radical Biol Med 2015;78:147-55.

12. Maleki A, Fard MK, Zadeh DH, Mamegani MA, Abasaizadeh S, Mazloomzadeh S. The relationship between plasma level of Se and preeclampsia. Hypertens Preg. 2011;30(2):180-7.

13. Rayman MP, Searle E, Kelly L, Johnsen S, BodmanSmith K, et al. Effect of selenium on markers of risk of pre-eclampsia in UK pregnant women: a randomised, controlled pilot trial. Brit $\mathrm{J}$ Nut. 2014;112(1):99-111.

14. Tara F, Maamouri G, Rayman MP, GhayourMobarhan M, Sahebkar A, Yazarlu O, et al. Selenium supplementation and the incidence of preeclampsia in pregnant women: randomized, double-blind, placebo-controlledtrial. Taiwan J Obstet Gynecol. 2010;49(2):181-7.

15. Gifford RW.Report of the National High Blood Pressure Education Program Working Group onHigh Blood Pressure in Pregnancy. Am J Obstet Gynaecol. 2000;183(1):S1-22.

16. Dwarkanath $\mathrm{P}$, Soares MJ, Thomas T, Vaz M, Swaminathan S, Kurpad AV. Semi quantitative food frequency questionnaire is a valid tool in the nutritional assessment of South Indian Pregnant women. Asia Pac J Public Health. 2014;26(5):494506.

17. Rayman MP, Bode P, Redman CWG. Low selenium status is associated with the occurrence of the pregnancy disease preeclampsia in women from the United Kingdom. Am J Obstet Gynecol. 2003; 189(5):1343-9.

Cite this article as: Kaveri V, Manjula SK, Sheela CN, Kurpad A, Dwarkanath P. Maternal serum selenium as a predictor of preeclampsia. Int J Reprod Contracept Obstet Gynecol 2018;7:4628-33. 